\title{
How to Make Traditional Advanced Mathematics Classrooms Walks out of MOOC Storm
}

\author{
Min ZOU, Rongsan CHEN and Meng SU \\ China University of Geosciences (Wuhan) School of Mathematics and Physics \\ Hubei, Wuhan 430074
}

\begin{abstract}
Specific to the great impacts incurred by MOOC storm on traditional advanced mathematics classrooms, this paper has provided specific and effective coping strategies. We have considered the factors of all aspects, and provided many suggestions, for instance improving the professional quality of teachers, actively adjusting teaching concept, converting traditional and single teaching mode, adopting rich and colorful teaching modes and methods, and utilizing the unique advantages of campus culture. It is hoped that MOOC and traditional advanced mathematics can supplement each other, and then improve the learning efficiency of students.
\end{abstract}

\section{Keywords-MOOC; Coping strategies; Advanced mathematics}

\section{INTRODUCTION}

In 2008, Canadian Scholar George Simmons and Stephen Downs cooperated and set the online open course of "connectivism and connectivity knowledge", marking the birth of "MOOC". In 2012, American famous colleges, including Stanford University, Harvard University and MIT successively released MOOC platform, and it was praised as "troika" of MOOC. Since then, MOOC storm has been fast spread worldwide, and attracted learners from above 220 countries, bringing huge impacts to traditional education like earthquake and tsunami. Free MOOC "has opened the gate to Ivy League for people". Since 2013, domestic colleges have successively joined in MOOC platform, and higher education has stepped into the era of MOOC; more and more people have participated in it, and enjoy the convenience and advantages brought by online learning.

MOOC is a kind of large-scaled and open online course, and can provide free online study for learners worldwide. It is a kind of course mode, and has big differences with a kind of resource mode network public courses. It has complete course structure, and includes course objective, course arrangements, homework, test and other series of links, and after completing the course, it is also applicable to participate in examinations to gain certificates. These courses are just like traditional college courses, which can gradually make the students grow into senior talents from beginners. The scope of courses will not only cover extensive scientific disciplines, such as mathematics, statistics, computer science, natural science and engineering, but also contain social society and humanities. Due to its advantages, MOOC has developed fast worldwide, and this has brought an unprecedented impact to traditional education mode; more and more people question the classroom teaching mode that has been inherited for thousands of years, and students are gradually lost. In traditional higher education, as the basic course for various colleges, the classroom teaching for Advanced Mathematics is an extremely important link; the blackboard and chalk have cultivated generations of talents. However, the emerging MOOC can not only provide rich and colorful leading learning resources to students, but also has more diversified and characteristic teaching modes than traditional teaching modes; students can select more suitable teachers as per their own interests and hobbies to teach them knowledge, and all of these excellent scholars from famous colleges can make boring mathematic formulas and theorems shine vigor, and make the learning process more interesting, so students are willing to participate, which will keep them away from traditional classrooms farther and farther. How to walk out of this MOOC storm has become the problem that shall be urgently solved. However, MOOC also has disadvantages, it has higher requirements for students' consciousness and selflearning capacity, and students cannot blindly rely on MOOC and keep themselves away from traditional classrooms. Thus, as teachers, we should organize teaching as per the detailed conditions of students specific to the advantages and disadvantages of MOOC, adjust our teaching methods, form our own teaching characteristics, and strive to improve our professional quality, gather all the advantages, combine traditional teaching mode and MOOC, complement each other, so that students can better learn knowledge in classrooms. In this case, we should realize the following aspects:

\section{IMPROVE TEACHERS' PROFESSIONAL QUALITY AND ACTIVELY ADJUST TEACHING CONCEPTS.}

The occurrence of MOOC is like a small stone breaking the calm lake of traditional classrooms; through participating in the learning of MOOC platform, students can contact with the courses of many famous teachers, and more teaching concepts, which have broadened their horizons, so they are more critical of the teachers' professional quality. In order to gain better teaching effect, attract students' attention, and mobilize students' enthusiasm, teachers should focus on the guidance in the teaching process, change the concept of the traditional classroom that takes the teacher and textbooks as the center, form the student-centered new concept, and make students think that they are the master of learning. In the classroom teaching process, teachers shall design more communication links between teachers and students, focus on students' absorption feedback about knowledge, mobilize and influence 
the emotions, feelings and enthusiasm when students are listening to lessons, build active classroom atmosphere, and let students wholeheartedly devote into the study, to largely improve learning efficiency. Besides, if students can apply their knowledge, and use simple mathematical models to lead students to think and solve problems, so students can gain the sense of achievement and increase their learning impetus. The main factor deciding whether students are interested in certain course is whether the teacher teaching the course can attract them in the teaching process, and if the teacher can explain profound theories in simple language and can let students absorb easily, students can gain the sense of achievement, and the desire to listen. However, in the advanced mathematics course system and even the entire mathematics system, most of them are boring theories difficult to understand and apply. If teachers merely repeat what the book says, derive and calculate step by step, it can be hard for students to learn, let alone digest and draw inferences. Thus, teachers shall deeply study the advanced mathematics course contents, mix the mathematic culture into the teaching process, make students become more interested in learning, and make them thoroughly understand that the entire theoretical system is more helpful. Meanwhile, it is supplemented by some interesting teaching activities related to the teaching contents. But these teaching activities cannot be realized via MOOC. As a compulsory public course, most colleges adopt unified course, unified teaching calendar and unified examination modes for the advanced mathematics; some teachers will neglect the differences of students in the specialty, absorption capacity and the foundation of mathematics during the teaching process, and will teach as per the unified teaching outline and teaching plan, so this has caused partial students in failing to catch up with the progress; they don't want to listen and then trap in a vicious circle of learning, and if this continues, they will lose learning confidence in traditional classroom teaching, and even cut classes and avoid learning with excuses. While MOOC has rich teaching resources, and learners can select suitable courses as per their own foundation of mathematics. MOOC can adopt various multi-media technologies in the teaching courses, and provide rich, diversified, distinct and vivid teaching experience and feelings for learners, and make students keep vigorous learning power and attentions. In this case, teachers must learn and skillfully master these technical measures, and present these information technologies in our traditional classrooms, improve the teaching artistry of traditional advanced mathematics, and optimize students' sensual experience. For instance, in the space analytic geometry, teachers can use multi-media technologies to show the curved surface and curve movements more vividly and intuitively. When teaching rotating curved surface, if we can dynamically demonstrate the translation of moving straight line along the baseline, students can better understand the definition of busbar and the baseline. In limit definition, it is also applicable to dynamically show cyclotomy, let students experience the unlimited increase of regular polygon edges inscribed in a circle; in the definition of the definite integral, it is also applicable to show subdivision infinity approximation, which can help students understand the contents. Meanwhile, while learning MOOC, students can naturally compare the famous teachers in MOOC with their own traditional classroom teachers, which can easily attach our weakness with others' strength, and then they are no longer willing to listen to their own teachers. Thus, teachers of advanced mathematics shall learn widely from others' strength, and strive to improve their own professional knowledge quality.

III. CONVERT TRADITIONAL SINGLE TEACHING MODE, AND ADOPT RICH AND DIVERSIFIED TEACHING MODE AND METHODS.

In order to cope with the strong impact of MOOC storm, new advanced mathematics classrooms shall change the previously single teaching mode, organize and use more diversified teaching mode, such as the heuristic, guided, and communication discussion type teaching methods. Teachers shall emphasize on mobilizing students' learning initiative, cultivate students' divergent and creative thoughts. Teachers should try to truly hand over the classroom to students, and sometimes, teachers merely need to accompany and guide students to find and solve problems, and make them feel the joy in the autonomous learning of knowledge. In classrooms, we can carry out classroom group discussion and other similar interactive teaching modes, mobilize students' learning enthusiasm and make them be drawn to traditional classrooms. This is something that MOOC cannot do. MOOC courses are fully taught on line, and when teaching the course, teachers cannot interact with students, or receive students' knowledge feedback and can merely predict the possible difficulties of students in the study as per their own several years of teaching experience. Besides, MOOC has an extremely high requirement for students' self-consciousness. However, the approach of keeping students at traditional classrooms cannot simply and roughly resist MOOC, on the contrary, teachers with relatively rich experience should actively help students select and provide qualified offline learning platform, encourage and supervise students to utilize these platforms after the class for preview and review on consolidation, and then yield twice the result with half the effort. In the teaching of advanced mathematics, teachers of advanced mathematics should integrate MOOC, regard students as the center, and MOOC as the tools, to fully utilize MOOC advantages, and then through the shared interschool qualified teaching resources, establish the mixed teaching mode that combined classroom education and network education, make student focus on traditional classrooms supplemented by MOOC, break through "cramming education" traditional teaching mode, validly learn knowledge, promote the reform of teaching contents, modes and methods reform, and improve the teaching quality of higher education.

\section{FULLY USE THE UNIQUE ADVANTAGES OF CAMPUS CULTURE THAT ARE NOT EQUIPPED IN MOOC.}

The essence of campus culture is a kind of unique cultural environment and cultural atmosphere at school; it includes campus construction design, campus landscape, greening and beautification, and other materialized contents, and also includes school tradition, school spirit, learning styles, interpersonal relationship, collective opinions, psychological atmosphere as well as various rules and regulations of the school and the non-standard codes of conduct that are formed by school members in joint activity contact, and it is the sum of material culture and spiritual culture formed and developed by 
the school itself. Campus culture should play an important role in the current higher education; it can edify students' sentiment, enlighten the students' mind, and promote students to develop comprehensively. After the campus culture has been formed in the school, corresponding value concept and behavioral norms will be established. When the value concept, behavior orientation and standard for partial members of the school are deviated, campus culture will exert its guiding function. The college campus culture can exert the effect of consolidating the solidarity and integration of members. After a kind of value concept is accepted and recognized by college students on campus, it will make teachers and students generate a strong sense of belonging and recognition, gather the thoughts of all teachers and students together, motivate the joint struggling objective, and then change spiritual emotions into a huge joint force. Campus culture can constantly promote the quality of teachers and students through activities outside of the class, such as social practice, social investigation, and social public activities. It is an indispensable mode to cultivate team spirits, and cooperation awareness. One takes the behavior of one's company; campus culture is the education resource with guiding function; as a kind of environment education force, it can exert a huge influence on students' healthy growth. Thus, as college students, it is requested to form correct value concept and the view of life under the edification of campus culture, rather than merely relying on MOOC and separating from the campus and classrooms.

\section{CONCLUSIONS}

Along with the change of times, traditional advanced mathematics classrooms have become more and more inadequate to the demands of modernized teaching reform. However, the occurrence of MOOC has brought a light to our teaching reform. MOOC is the result of the constant deepening and exploration of education reform worldwide, and the application popularity of information technology in education field has broken through time restriction, overturned the enclosures of school, and opened "a magical door" for education. The "magical" education has realized the maximum teaching effect of education, make students listen to classes at any time, overturned traditional college classroom teaching mode, and exerted an important promotion effect on promoting education fairness, and realizing the high-qualified and connotative development of higher education; besides, it has also provided a new development thought for the classroom teaching reform of higher education in our country. It has narrowed the distance between normal students and famous schools worldwide, make people enjoy qualified education resources, changed people's opinions towards traditional higher education, and bring new challenges and opportunities for traditional teaching, especially higher education. However, when being compared with traditional advanced mathematics classrooms, it also has its own disadvantages. In the face of MOOC storm, advanced mathematics classrooms shall take the essence and discard the dregs, face it with a positive attitude, fully exert its advantages, and make it become a learning weapon of advanced mathematics.

\section{ACKNOWLEDGMENT}

About the author: Min ZOU (May, 1981), female, Han nationality, born in Xiantao of Hubei, a master degree candidate and lecturer, and the research direction is: Vibration theory about partial differential equation.

\section{REFERENCES}

[1] Yan ZHAO, Challenges of MOOC for College Teaching and the Coping Strategies[J] Journal of Higher Education, 2015(7): 34-35;

[2] Wenjun YAN, Rational Coping with MOOC and Colleges [J], Chongqing Higher Education Research, 2014(1): 10-13;

[3] Chunman ZHENG, Yujie LI, Nan HUANG et al., Reflections on the Coping Strategies and Reform of Course Teaching under MOOC Challenges[J], Journal of Higher Education, 2017(5): 97-99;

[4] Min ZOU, Rongsan CHEN, Qingxia MA. How to Let Traditional Advanced Mathematics Classrooms under Network Information Cope with MOOC Storm [J]. Information Recording Material, 2018, 19 (01): 147-148. 